\title{
EXPERIMENTAL INVESTIGATION ON CUTTING FORCES, SPECIFIC CUTTING PRESSURE, CO-EFFICIENT OF FRICTION AND SHEAR ENERGY IN TURNING OF HSLA STEEL
}

\author{
Balasubramaniyan Singaravel, Thangiah Selvaraj \\ Production Engineering Department, National Institute of Technology, Tiruchirappalii, Tamilnadu, India \\ Corresponding author: \\ Balasubramaniyan Singaravel \\ Research Scholar \\ National Institute of Technology \\ Production Engineering Department \\ National Institute of Technology \\ Tamilnadu, India \\ phone: $(+99) 9940870470$ \\ e-mail:vel_singara@yahoo.co.in
}

Received: 31 December 2015

Accepted: 26 February 2016

\begin{abstract}
Machinability study of a material is used to find the ease and difficulty during machining operation. High Strength Low Alloy (HSLA) medium carbon steel (EN25 steel) is considered to possess better mechanical properties than carbon steel. In this work, an attempt is made to experimentally investigate and realize the machinability of EN25 steel during turning with coated carbide tools. The effects of machining parameters on cutting force components, Specific Cutting Pressure (SCP), co-efficient of friction and shear energy are analysed during the investigation. The results of the investigation revealed that the mentioned machinability characteristics are necessary and essential to evaluate the machinability of HSLA steel effectively.
\end{abstract}

KEYWORDS

turning, HSLA steel, cutting force, SCP; co-efficient of friction; shear energy.

\section{Introduction}

Turning is one of the basic machining operations in engineering industries. The general cutting force can be divided into three cutting force components namely main cutting force component, feed force component and thrust component. When the cutting force acts along the direction of cutting speed it is called the main cutting force component. Feed force component acts along the direction of the tool feed and thrust force component acts perpendicular to the turned surfaces. These forces influence machinability of any material, generation of heat, tool wear, quality of the machined surface and accuracy of the work piece. Also, these force components are used to estimate power requirements, design of machine tool elements, tool holders and fixtures. The measurement of these cutting force components are used to estimate the SCP during machining operation. SCP di- rectly influences the status of the cutting wedge and it can be used as an indicator of the efficiency of a process. The frictional co-efficient can be defined by the ratio of normal force to the tangential force acting on the rake face of the cutting tool. Co-efficient of friction is an indicator to improve the cutting tool performance. This co-efficient is calculated from the measured cutting forces during machining. The coefficient of friction in machining is mainly influenced by cutting speed, feed rate, depth of cut and rake angle. Shear energy determination is an important parameter for consumption of energy in plastic deformation of shear plane. According to Ernst and Merchant [1], the work material deforms when the shear plane attains the shear strength of the work material. Also, in turning operation, cutting fluid acts as a lubricant, which is extensively used to improve the tribological characteristics of the workpiece-tool-chip system. In machining operation cutting fluid is used 
to improve the tool life, surface finish and reduce the cutting force.

\section{Literature review}

Hakim et al. [2] analyzed the effect of machining parameter on cutting force component in hard turning of AISI T15 high speed steel. The cutting force during the turning of the alloy steel was remarkably affected by the type of the chip produced. Selvaraj et al. [3] optimized cutting parameters using Taguchi method in dry turning of stainless steel. The result showed that feed rate was the significant factor to control the cutting force components. Lawal et al. [4] evaluated the effect of cutting fluids on cutting force components in turning of AISI 4340 steel using Taguchi method. The results showed that cutting speed and cutting fluid were significant factors on cutting force measurements. Mandal et al. [5] investigated the effect of process parameters on cutting force components in turning of zirconia toughened alumina coated inserts. A mathematical model was developed using regression analysis for forces and the results indicated the effectiveness of the approach. Suresh et al. [6] analyzed cutting force component using Taguchi method in turning of EN24 steel using coated tool. The result concluded that cutting force variation was probably due to temperature rise in the shear plane area. Devillez et al. [7] analyzed the effect of cutting force component in dry turning of Inconel 718. The result revealed that cutting speed is the predominant factor to control the forces in turning operation. Thakur et al. [8] experimentally investigated the effect of machining parameters on cutting force components in high speed turning of Inconel 718 . The result mentioned that cutting force values decreased at a higher level of cutting speed due to temperature increase with increase in cutting speed. Sharma et al. [9] developed a mathematical model to create relationship between machining parameters and cutting force components. The developed model was used to predict the accurate results. Thakur et al. [10] experimentally analyzed the effect of process parameters on SCP on Inconel 718 in turning operation. The result revealed that SCP was used to predict loss of form stability of the cutting wedge. Sreejith et al. [11] analyzed the effect of process parameters on SCP in turning of composite material using PCBN tools. The results concluded that cutting speed in the range of $100-200 \mathrm{~m} / \mathrm{min}$ the SCP was constant. Davim and Figueira [12] evaluated the machinability in terms of SCP in turning of tool steel D2 with ceramic cutting tools. A statistical analysis was carried out using orthogonal array and ANOVA to realize the machinability characteristics. The result indicated that reduced SCP was achieved at increased feed rate due to the change of cross sectional area of the uncut chip thickness. Davim [13] conducted SCP analysis on metal matrix composite. The results revealed that SCP increased with increase in machining time. Davim and Mata [14] studied machinability study on glass fiber reinforced using polycrystalline diamond and carbide cutting tools. The result showed that surface roughness and SCP were influenced by feed rate. Also, a machinability characteristic is proposed in terms of surface roughness and SCP called machinability index. Davim and Mata [15] evaluated a machinability index in terms of surface quality and SCP in turning of fiber reinforced plastics with polycrystalline diamond tool. The result revealed that surface roughness increased with feed rate and decreased with cutting speed. Also, SCP influenced by feed rate and cutting speed is insignificant. Çakır et al. [16] studied the effects of cutting fluid, gas (oxygen, nitrogen and carbon dioxide) application and dry cutting on cutting force components, co-efficient of friction and shear angle in turning of AISI 1040 steel. The results revealed that gas and wet turning gave better performance than dry turning. Duflou et al. [17] conducted the determination of energy required to remove the material during machining operation. They mentioned the amount of energy required to remove the material by shear and friction energy. Pawade et al. [18] analyzed the shear energy required to deform during plastic deformation in turning of Inconel 718. The result revealed that shear energy is increased at cutting speed of $125 \mathrm{~m} / \mathrm{min}$ and decreased with feed rate of $0.10 \mathrm{~mm} / \mathrm{rev}$.

From the literature review, it has been found that limited amount of works were carried out on combined analysis of cutting force components, SCP, coefficient of friction and shear energy in turning operation. Hence an effort has been made to analyze the effect of machining parameters on the above mentioned objective parameters in turning of EN25 steel with CVD coated carbide tool.

\section{Experimental setup}

In this experimental analysis, work piece material considered is EN25 steel and the major elements presence in EN25 steel are given in Table 1. This material possesses high mechanical strength and corrosion resistance than carbon steel, hence it is widely used in heavy duty drive shafts [19]. The work pieces selected are round rod with $38 \mathrm{~mm}$ diameter and the turning experiments are conducted on $\mathrm{CNC}$ turning 
center with 7.5 KW spindle power in a coolant environment. Figure 1 shows the experimental setup of CNC turning center with cutting force measurement setup.

Table 1

Chemical composition (wt \%) of EN25 steel.

\begin{tabular}{c|c}
\hline Element & wt \% \\
\hline Carbon & 0.293 \\
\hline Silicon & 0.185 \\
\hline Manganese & 0.629 \\
\hline Nickel & 2.49 \\
\hline Chromium & 0.577 \\
\hline Molybdenum & 0.51 \\
\hline Sulphur & 0.02 \\
\hline Phosphorous & 0.02
\end{tabular}

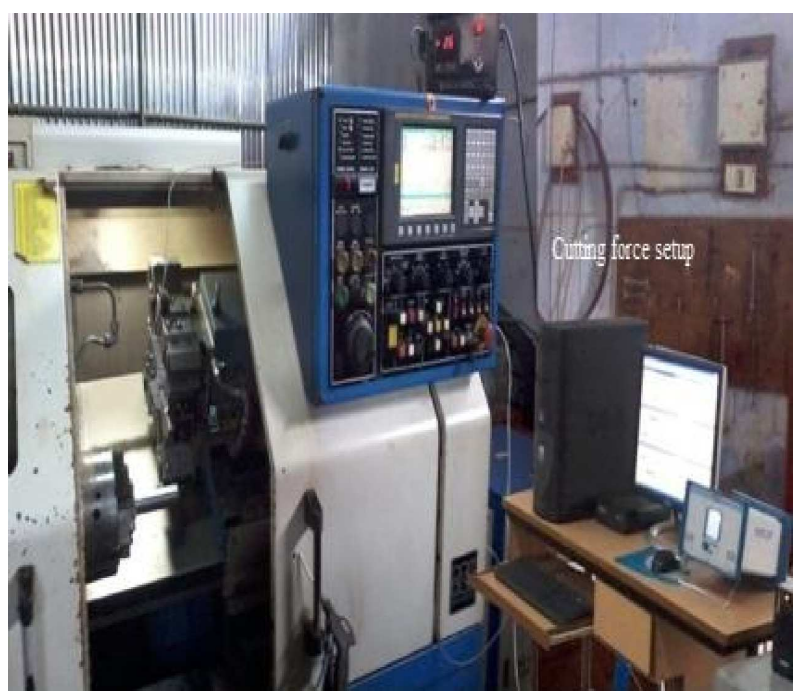

Fig. 1. Experimental setup.

The cutting tool material used is Chemical Vapour Deposition (CVD) coated carbide tool with ISO geometry of CNMG 120404. This coated tool consists of three layers $\left(\mathrm{TiN} / \mathrm{TiCN} / \mathrm{AL}_{2} \mathrm{O}_{3}\right.$ ), in which TiN affords heat resistant and low co-efficient of friction, TiCN affords wear resistant and thermal stability and $\mathrm{Al}_{2} \mathrm{O}_{3}$ affords crater wear resistance as a result of high-temperature conditions and hardness.

Taguchi based orthogonal array is used to minimize the experiments to be carried out. In this work, $L_{18}$ orthogonal array is used to conduct turning operations [20]. The selected machining parameters are cutting speed, feed rate and depth of cut in order to analyze cutting force components, SCP, co-efficient of friction and shear energy. The machining parameters are identified with multi-level factors (i.e) three level factors to analyze the non linearity effect of pa- rameters. The levels of selected machining parameters are presented in Table 2.

Table 2

Machining parameters and their levels.

\begin{tabular}{l|c|c|c}
\hline Factors & Level 1 & Level 2 & Level 3 \\
\hline Cutting speed, m/min & 95 & 155 & 215 \\
\hline Feed rate, mm/rev & 0.07 & 0.15 & 0.23 \\
\hline Depth of cut, mm & 0.5 & 1.0 & 1.5 \\
\hline
\end{tabular}

The cutting force components during the turning of EN25 steel are measured using tri axial force dynamometer. This Kistler type piezo electric dynamometer (model 9257B) can measure the force signals while cutting process in three directions. The signal is acquired by data acquisition system, which consists of charge amplifier and a personal computer with an analog to digital convertor card to capture the force signal. The continuous flow of data for force in all directions can be measured by using Dynoware software installed in the computer. The SCP is determined from the main cutting force component using the following equations $[12,13]$.

$$
K_{C}=\frac{F_{c}}{f \cdot a},
$$

where $K_{c}$ - Specific cutting force component into the direction of $F_{c}, \mathrm{~N} / \mathrm{mm}^{2}, F_{c}$ - Main cutting force component, $\mathrm{N}, f-$ Feed rate, $\mathrm{mm} / \mathrm{rev}, a-\operatorname{depth}$ of cut, mm.

The co-efficient of friction of the rake face of the cutting tool can be determined with the help of measured cutting force components and Merchant's theory as given below [15]

$$
\mu=\frac{\left(F_{t} \cos \alpha+F_{c} \sin \alpha\right)}{\left(F_{c} \cos \alpha-F_{t} \sin \alpha\right)}
$$

where $\mu$ represents the co-efficient of friction, $F_{c}$ represents the main cutting force component, $F_{t}$ is the radial/thrust force component and $\alpha$ is the rake angle.

In turning, the shear energy $\left(\tau_{e}\right)$ can be calculated by $[16,17]$

$$
\tau_{e}=\frac{\tau \times V_{s}}{V \times \sin \varnothing}
$$

where $\tau$ represents shear stress, $V_{s}$ represents shear velocity, $V$ represents cutting velocity and $\varnothing$ represents shear angle. The following Eqs. (4), (6) and (7) are used to determine the shear stress, shear velocity and shear angle respectively.

$$
\tau=\frac{F_{s}}{A \times \sin \varnothing},
$$

where $F_{s}$ represents shear force and A represents shear area. 
Management and Production Engineering Review

Table 3

\begin{tabular}{c|c|c|c|c|c|c|c|c|c}
\hline Sl.no & $\begin{array}{c}\text { Cutting } \\
\text { speed } \\
{[\mathrm{m} / \mathrm{min}]}\end{array}$ & $\begin{array}{c}\text { Feed rate } \\
{[\mathrm{mm} / \mathrm{rev}]}\end{array}$ & $\begin{array}{c}\text { Depth } \\
\text { of cut } \\
{[\mathrm{mm}]}\end{array}$ & $\begin{array}{c}\text { Main cutting } \\
\text { force } \\
\text { component } \\
{[\mathrm{N}]}\end{array}$ & $\begin{array}{c}\text { Feed force } \\
\text { component } \\
{[\mathrm{N}]}\end{array}$ & $\begin{array}{c}\text { Radial } \\
\text { force } \\
\text { component } \\
{[\mathrm{N}]}\end{array}$ & $\begin{array}{c}\text { SCP } \\
{\left[\mathrm{N} / \mathrm{mm}^{2}\right]}\end{array}$ & $\begin{array}{c}\text { Shear } \\
\text { energy } \\
{\left[\mathrm{N} / \mathrm{mm}^{2}\right]}\end{array}$ & $\begin{array}{c}\text { Co-efficient } \\
\text { of friction }\end{array}$ \\
\hline 1 & 95 & 0.07 & 0.5 & 379 & 288 & 248 & 10828.57 & 7129.21 & 0.513872 \\
\hline 2 & 95 & 0.15 & 1.0 & 429 & 364 & 319 & 2860.00 & 1525.88 & 0.592167 \\
\hline 3 & 95 & 0.23 & 1.5 & 816 & 441 & 414 & 2365.21 & 1812.85 & 0.381855 \\
\hline 4 & 155 & 0.07 & 0.5 & 312 & 254 & 212 & 8914.28 & 5300.39 & 0.536063 \\
\hline 5 & 155 & 0.15 & 1.0 & 414 & 308 & 264 & 2760.00 & 1937.48 & 0.499091 \\
\hline 6 & 155 & 0.23 & 1.5 & 507 & 379 & 324 & 1469.56 & 1021.53 & 0.50031 \\
\hline 7 & 215 & 0.07 & 1.0 & 262 & 236 & 204 & 3742.85 & 1728.18 & 0.622536 \\
\hline 8 & 215 & 0.15 & 1.5 & 364 & 286 & 248 & 1617.77 & 1006.82 & 0.537676 \\
\hline 9 & 215 & 0.23 & 0.5 & 402 & 254 & 196 & 3495.65 & 2483.66 & 0.363785 \\
\hline 10 & 95 & 0.07 & 1.5 & 373 & 459 & 240 & 3552.38 & 2428.5 & 0.504195 \\
\hline 11 & 95 & 0.15 & 0.5 & 455 & 288 & 325 & 6066.66 & 3433.67 & 0.566607 \\
\hline 12 & 95 & 0.23 & 1.0 & 526 & 371 & 386 & 2286.95 & 1423.85 & 0.583679 \\
\hline 13 & 155 & 0.07 & 1.0 & 276 & 248 & 212 & 3942.85 & 2021.15 & 0.613448 \\
\hline 14 & 155 & 0.15 & 1.5 & 342 & 302 & 288 & 1520.00 & 698.263 & 0.677036 \\
\hline 15 & 155 & 0.23 & 0.5 & 397 & 204 & 184 & 3452.17 & 2451.27 & 0.341696 \\
\hline 16 & 215 & 0.07 & 1.5 & 257 & 242 & 207 & 2447.61 & 1444.99 & 0.645645 \\
\hline 17 & 215 & 0.15 & 0.5 & 335 & 226 & 181 & 4466.66 & 2990.46 & 0.411778 \\
\hline 18 & 215 & 0.23 & 1.0 & 364 & 238 & 194 & 1582.60 & 1045.05 & 0.405136 \\
\hline
\end{tabular}

The shear force $F_{s}$ can be determined by

$$
F_{s}=F_{c} \cos \varnothing-F_{t} \sin \varnothing .
$$

The shear area can be determined by

$$
\mathrm{A}=\text { chip width } \times \text { chip thickness. }
$$

The shear velocity can be estimated by

$$
V_{s}=\frac{V \cos \alpha}{\cos (\varnothing-\alpha)} \text {. }
$$

The shear angle can be calculated by

$$
\begin{gathered}
\tan \varnothing=\frac{r \cos \alpha}{1-r \sin \alpha}, \\
r=\frac{a}{a_{c}},
\end{gathered}
$$

where $r$ represents cutting ratio, a represents depth of cut and $a_{c}$ represents chip thickness.

Table 3 shows the observed values of various output parameters.

\section{Results and discussions}

In this investigation, objective parameters considered are namely cutting force components, SCP, co-efficient of friction and shear energy. Table 3 shows the experimental results obtained using $L_{18}$ orthogonal matrix. In this experimental study, cutting force components are minimization type objectives, hence 'smaller-the-better' concept is considered. Based on the main effects plot (Figs. 2, 3 and 4), minimum cutting forces of turning process is the combination of cutting speed of $215 \mathrm{~m} / \mathrm{min}$, feed of $0.07 \mathrm{~mm} / \mathrm{rev}$ and depth of cut of $1.0 \mathrm{~mm}$. From the experimental results, the main cutting force components have higher magnitude than feed force and radial force components. The main cutting force value decreased at high cutting speed. This is due to the high cutting speed, shear angle increases and hence minimium shear plane area. Then, the cutting force value increased when the feed rate value increased due to the increase of contact area between the cutting tool and work piece. Also, at low feed rate there is a small resistance to cutting tool and at high feed rate the work material provides more resistance to cutting tool and hence an increase of friction which directs an increment of cutting force.

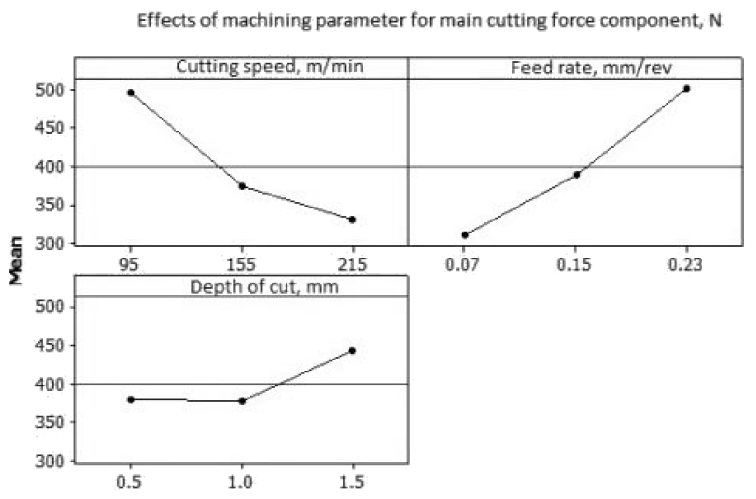

Fig. 2. Effects of machining parameter for main cutting force component. 
Effects of machining parameter for feed force component, $\mathrm{N}$

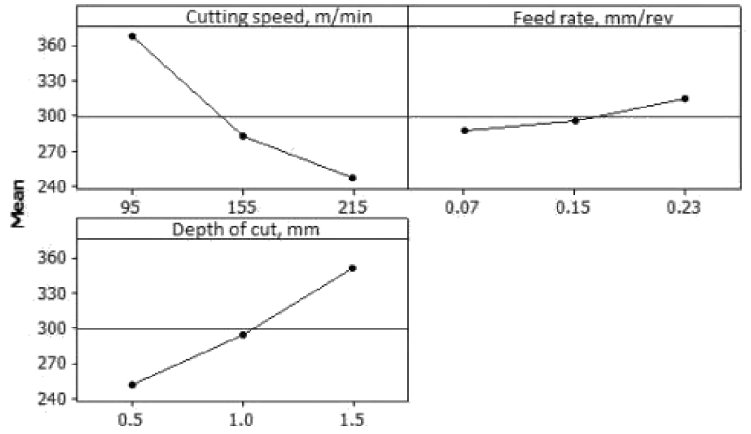

Fig. 3. Effects of machining parameter for feed force component.

Effects of machining parameter for radial force component $\mathrm{N}$
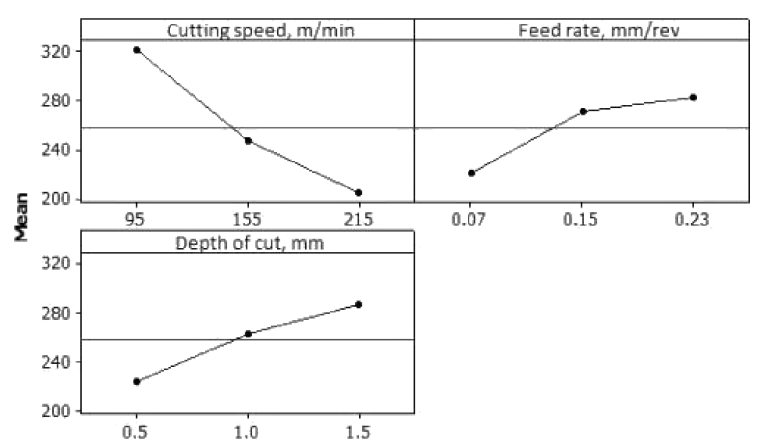

Fig. 4. Effects of machining parameter for radial force component.

In machinability evaluation of HSLA steel, the SCP is an important process indicator and it is usually determined by given chip cross section and variation of cutting force. Figure 5 represents variation of SCP with various combination of machining parameter levels. The SCP value increases at lower level of cutting speed with higher feed rate due to high co-efficient of friction between cutting tool and work piece material. The SCP values are better at a higher value of cutting speed. When the feed rate is increased, the cross sectional area of the uncut chip thickness increases, hence SCP gets reduced. Cutting fluid is used to reduce co-efficient of friction between the work piece and cutting tool material. This cutting fluid acts as a thin boundary film between the tool-work piece interfaces. The SCP influences the cutting wedge, which can be used as a process indicatior. Hence, any variation in SCP can be lead to the loss of stability of the cutting wedge.

From the experimental result of shear energy (Fig. 6), it is observed that the shear energy is higher at the lowest cutting speed and feed rates. This is due to the smaller area of cross-section involved in shearing deformation. At lower cutting speed, cutting forces increases, the cross sectional area in shear gets reduced and therefore larger shear energy is re- quired for machining. Further increase in the cutting speed and feed rate, reduces the shear energy. This shear energy study is important for energy consumed for plastic deformation in shear plane.

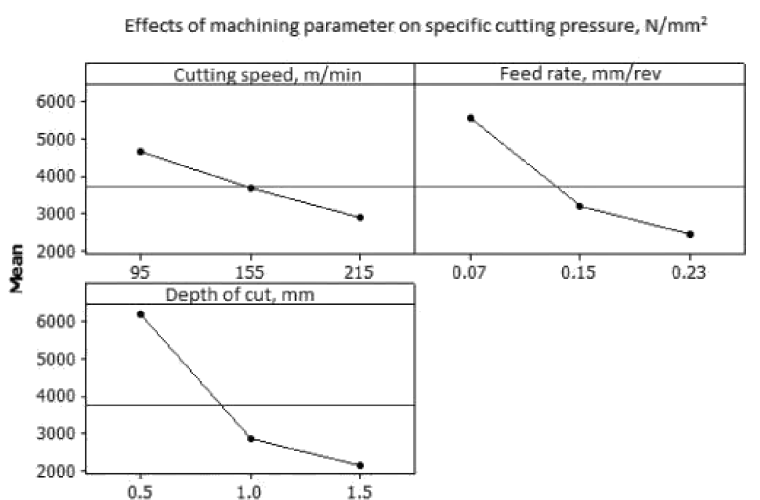

Fig. 5. Effects of machining parameters on specific cutting pressure.

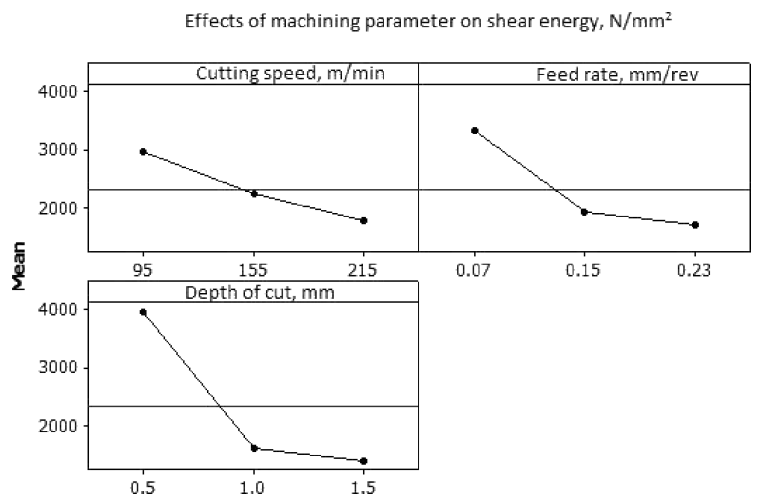

Fig. 6. Effects of machining parameter on shear energy.

Figure 7 shows the effects of machining parameters on co-efficient of friction, minimum values obtained at high cutting speed due to smaller contact area and larger shear plane during machining. Also, at low depth of cut, thin chips are formed which resulted in higher cutting ratio and hence low coefficient of friction is obtained.

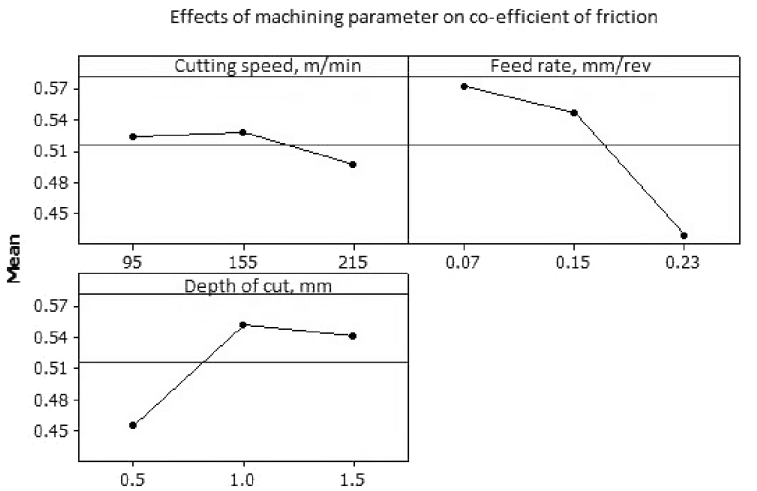

Fig. 7. Effects of machining parameter on co-efficient of friction. 


\section{Conclusions}

This study analyzed the effects of machining parameters for machinability characteristics in turning operation using coated tools. The following conclusions are derived from this analysis:

- The effect of process parameters are analyzed for cutting force components, SCP, co-efficient of friction and shear energy for the enhancement of machining performance.

- The minimum value of cutting force components are obtained at higher value of cutting speed and lower value of feed rate and depth of cut.

- The SCP values are increased at lower level of cutting speed and higher level of feed rate due to high co-efficient of friction between the work piece material and cutting tool.

- The minimum shear energy for plastic deformation is achieved at higher level of cutting speed and feed rate.

- The minimum co-efficient of friction between toolchip interface is obtained at higher cutting speed due to smaller contact area and larger shear plane angle during shearing deformation.

\section{References}

[1] Ernst H., Merchant M.E., Chip formation, friction and high quality machined surfaces, Trans. ASME, 29, 299-328, 1941.

[2] El Hakim M.A., Shalaby M.A., Veldhuis S.C., Dosbaeva G.K., Effect of secondary hardening on cutting forces, cutting temperature, and tool wear in hard turning of high alloy tool steels, Measurement, 65, 233-238, 2015.

[3] Selvaraj D.P., Chandramohan P., Mohanraj M., Optimization of surface roughness, cutting force and tool wear of nitrogen alloyed duplex stainless steel in a dry turning process using Taguchi method, Measurement, 49, 205-21, 2014.

[4] Lawal S.A., Choudhury I.A., Nukman Y., Experimental Evaluation and Optimization of Flank Wear During Turning of AISI 4340 Steel with Coated Carbide Inserts Using Different Cutting Fluids, Journal of IEI (India): Series C., 96, 21-28, 2015.

[5] Mandal N., Doloi B., Mondal B., Force prediction model of Zirconia Toughened Alumina (ZTA) inserts in hard turning of AISI 4340 steel using response surface methodology, Int. J. Precis. Eng. Manuf., 13, 1589-1599, 2012.

[6] Suresh R., Basavarajappa S., Samuel G.L., Some studies on hard turning of AISI 4340 steel using multilayer coated carbide tool, Measurement, 45, 1872-1884, 2012.

[7] Devillez A., Le Coz G., Dominiak S., Dudzinski D., Dry machining of Inconel 718, workpiece surface in- tegrity, J. Mater. Process. Tech., 211, 1590-1598, 2011.

[8] Thakur D.G., Ramamoorthy B., Vijayaraghavan L., Machinability investigation of Inconel 718 in highspeed turning, Int. J. Adv. Manuf. Technol., 45, 421429, 2009.

[9] Sharma V.S., Dhiman S., Sehgal R., Sharma S.K., Estimation of cutting forces and surface roughness for hard turning using neural networks, J. Intell. Manuf., 19, 473-483, 2008.

[10] Thakur D.G., Ramamoorthy B., Vijayaraghavan L., Study on the machinability characteristics of superalloy Inconel 718 during high speed turning, Mater. \& Des., 30, 1718-1725, 2009.

[11] Sreejith P.S., Krishnamurthy R., Malhotra S.K., Effect of specific cutting pressure and temperature during machining of carbon/phenolic ablative composite using PCBN tools, J. Mater. Process. Tech., 183, 88-95, 2007.

[12] Davim J.P., Figueira L. Machinability evaluation in hard turning of cold work tool steel (D2) with ceramic tools using statistical techniques, Mater. \& Des., 28, 1186-1191, 2007.

[13] Davim J.P. Diamond tool performance in machining metal-matrix composites, J. Mater. Process. Tech., 128, 100-105, 2002.

[14] Davim J.P., Mata F. A new machinability index in turning fiber reinforced plastics, J. Mater. Process. Tech., 170, 436-440, 2005.

[15] Davim J.P., Mata F., New machinability study of glass fibre reinforced plastics using polycrystalline diamond and cemented carbide (K15) tools, Mater. \& Des., 28, 1050-1054, 2007.

[16] Çakır O., Kıyak M., Altan E., Comparison of gases applications to wet and dry cuttings in turning, J. Mater. Process. Tech., 153, 35-41, 2004.

[17] Duflou JR., Kellens K., Guo Y., Dewulf W., Critical comparison of methods to determine the energy input for discrete manufacturing processes, CIRP Ann-manuf Techn., 61, 63-66, 2012.

[18] Pawade R.S., Sonawane H.A., Joshi S.S., An analytical model to predict specific shear energy in highspeed turning of Inconel 718, Int. J. Mach. Tool. Manu., 49, 979-990, 2009.

[19] Babu P.D., Buvanashekaran G., Balasubramanian K.R., Experimental investigation of laser transformation hardening of low alloy steel using response surface methodology, Int. J. Adv. Manuf. Technol., 67, 1883-1897, 2013.

[20] Gupta M., Kumar S., Investigation of surface roughness and MRR for turning of UD-GFRP using PCA and Taguchi method, Jestech., 1, 70-81, 2015.

Volume 7 • Number 1 • March 2016 